\title{
PENGENALAN DAN PELATIHAN MAPLE GUNA MENINGKATKAN HASIL BELAJAR DAN PEMAHAMAN MATEMATIKA
}

\section{MAPLE INTRODUCTION AND TRAINING \\ TO INCREASE LEARNING RESULTS AND UNDERSTANDING OF MATHEMATICS}

\author{
Oleh: \\ Dian Agustina, Etis Sunandi, Herlin Fransiska \\ Jurusan Matematika FMIPA Universitas Bengkulu \\ dianagustina117@gmail.com,etiss18@gmail.com,lynnandt@gmail.com
}

\begin{abstract}
The training and introduction of MAPLE is aimed to improving SMA Negeri 8 Kota Bengkulu students' logic and analysis ability to solve math problems. The steps taken are to prepare syllabus and MAPLE training material module that can be used as reference in the implementation of coaching, then carry out training for one month. From the pre-test and post-test results it can be concluded that there is a significant difference from the learning result before and after knowing and using MAPLE. The average post-test score is much greater when compared with the student's pre-test score. Paired sample testing gives a $t$-value of 24,079 with p-value 0.000. It can be concluded that the average pre-test and post-test values are significantly different. This means that the introduction and training of MAPLE in SMA Negeri 8 gives a real influence on students' mathematics learning outcomes.
\end{abstract}

Keywords: MAPLE Training, Mathematics

\section{PENDAHULUAN}

Matematika merupakan mata pelajaran yang dipelajari hampir di setiap jenjang pendidikan karena itu hampir setiap orang mengenal matematika. Tetapi, matematika dikenal sebagai mata pelajaran yang menjadi momok karena di anggap sulit. Yang membuat matematika dirasa sulit bahkan oleh mahasiswa matematika sendiri adalah karena daya abstraksi yang lemah (Ulum, 2015). Pemahaman matematika dari jenjang pendidikan sekolah dasar hingga sekolah menengah atas dianggap semakin sulit, terlebih jika pada saat lulus SMA siswa memilih kuliah di jurusan sains yang tidak terlepas dari matematika seperti program studi matematika dan statistika. Pada jenjang pendidikan SMA, matematika sudah dianggap sangat sulit dipahami. Hal ini karena materi pada saat SMA sudah memasuki level abstrak. Hal ini membuat alat bantu pemahaman matematika menjadi sangat penting dan dibutuhkan oleh siswa.

Pemahaman matematika seperti tersebut di atas tentunya tidak lepas dari proses pembelajaran yang digunakan. Proses pembelajaran di sekolah biasanya hanya 
menggunakan system TCL (Teacher Centered Learning), yang berpusat kepada guru. Apabila sistem ini kemudian digandengkan dengan SCL (Student Centered Learning), yang berpusat pada siswa, maka proses pembelajaran akan lebih meberikan hasil yang baik. Pemahaman siswa akan lebih mendalam karena siswa mengalami sendiri semua prosesnya, mulai dari menemukan masalah hingga menyelesaikannya.

Matematika merupakan dasar perkembangan teknologi. Untuk mendukung hal ini tentunya telah dikembangkan juga alat bantu memahami matematika. Hal ini dapat dilihat banyak sekali aplikasi-aplikasi komputer yang menunjang pembelajaran matematika seperti MAPLE, SAS, R, EVIEWS, MATLAB, Cabri, Geogebra, Mathemania, Matematica, dan lain sebagainya. Perkembangan teknologi ini dapat dimanfaatkan oleh kalangan pendidikan untuk mempermudah memahami matematika. Dalam perkembangannya, matematika SMA sering ditemukan masalah mencari nilai dari suatu limit fungsi, bagaimana menurunkan/diferensial suatu fungsi, menggambar grafik fungsi, teknik integrasi, menentukan luas daerah, volume benda putar, dan lain-lain. Perhitungan tersebut memerlukan pemahaman yang baik mengenai materi tersebut. Selain itu, dalam menyelesaikannya memakan waktu yang cukup lama karena memerlukan ketelitian dan grafik yang benar. Misalnya saja kita akan mencari luas daerah/volume benda putar dari fungsi tertentu, sehingga kita harus membuat grafiknya terlebih dahulu. MAPLE merupakan software dasar matematika yang dapat menjadi salah satu alternatif guna menolong permasalahan tersebut, sehingga permasalahan diferensial-integral tersebut dapat dipecahkan secara efektif, efisien, dan hasilnya sangat akurat (Anonim, 2007). Sehingga pelatihan MAPLE menjadi penting guna membantu pemahaman matematika khususnya SMA hingga perguruan tinggi.

SMA Negeri 8 Kota Bengkulu merupakan salah satu SMA yang berada di Kota Bengkulu dan berjarak cukup dekat dengan Universitas Bengkulu. SMA yang berdiri sejak 1998 ini merupakan sekolah yang tergolong menengah ke bawah dari segi kualitas input siswa, sosial dan ekonomi siswa dan juga kondisi sekolah dan lingkungannya, namun peminat SMA ini tergolong cukup banyak. Hal ini ditunjukkan dengan jumlah siswa \pm 580 orang ( \pm 30 siswa/kelas). Tenaga pendidik di sekolah ini menuturkan bahwa pemahaman metamatika di sekolah ini tergolong lemah. Sehingga materi pelajaran matematika belum dapat diserap dengan baik. Dalam kegiatan penunjang pembelajaran, pelajaran matematika juga belum menjadi fokus sekolah. Hal ini terlihat dari kegiatan ekstrakurikuler yang lebih difokuskan pada kegiatan di bidang Olahraga, PRAMUKA, PASKIBRAKA, PMI dan Seni. Kondisi sosial dan ekonomi siswa juga membuat siswa belajar memahami matematika hanya dari pelajaran sekolah, tanpa ada tambahan belajar diluar sekolah seperti mengikuti bimbingan belajar maupun membentuk kelompok belajar. Kondisi ini mendorong dosen FMIPA Matematika, khususnya tim ini, untuk memberikan pelatihan tentang alat bantu memahami matematika.

Berdasarkan uraian yang dikemukakan di atas, maka masalah-masalah yang akan diangkat pada pengabdian masyarakat di SMA Negeri 8 Kota Bengkulu adalah bagaimana 
memberikan pelatihan dan pembinaan kepada siswa SMA tersebut tentang penggunaan software MAPLE sebagai alat bantu belajar matematika sehingga pemahaman matematika dapat menjadi lebih mudah, efektif dan efisien oleh siswa dengan keterbatasan input, sosial dan ekonomi siswa tersebut. Untuk itu kegiatan pengabdian ini bertujuan untuk mengetahui pengaruh kegiatan pengenalan dan pelatihan MAPLE pada siswa SMA Negeri 8 Kota Bengkulu terhadap pemahaman dan hasil belajar matematika.

\section{METODE PENGABDIAN}

Kegiatan pengabdian ini dilakukan di SMA Negeri 8 Kota Bengkulu pada 25 April 30 September 2016 dengan khalayak sasaran utama adalah siswa-siswi terpilih. Hal ini didasarkan agar keefektifan dalam pembinaan dapat berjalan dengan baik. Dalam pelaksanaanya tim Jurusan Matematika berkoordinasi dengan guru matematika dan Kepala Sekolah. Komputer atau laptop dengan instalasi program MAPLE merupakan alat bantu utama beserta modul pelatihan yang telah disiapkan oleh tim pengabdian.

Metode pelaksanaan kegiatan ini dilaksanakan dalam beberapa tahap. Berikut tahapan dan rencana kegiatan yang akan dilakukan:

1. Menyusun silabus pelatihan software MAPLE

Penyusunan silabus ini akan melibatkan bidang yang berbeda satu sama lainnya, Aritmatika, Aljabar, Statistika, Kombinatorik, dan Geometri.

2. Menyusun dan mengumpulkan materi-materi pembinaan yang sudah disusun disesuaikan dengan silabus pelatihan. Materi-materi tersebut disusun dalam bentuk modul. Langkah kedua ini ditempuh untuk menginventarisir semua bahan yang telah ada, untuk dapat disingkronisasikan dengan silabus yang ada.

3. Melaksanakan pre-test sebelum kegiatan pembinaan dimulai.

Tahap ini berjalan setelah modul pada langkah 2 terbentuk. Pada tahap ini, akan dilihat seberapa besar kapasitas/kemampuan siswa mengenai pemahaman matematika secara teori.

4. Melaksanakan kegiatan pembinaan

Tahap ini merupakan inti dari kegiatan pengabdian, dimana kurang lebih 4 pertemuan akan diberikan pembimbingan materi pelatihan. Pelatihan diberikan dalam bentuk praktikum.

5. Melakukan post-test

Pada tahap ini, akan dilihat seberapa besar peningkatan kapasitas/kemampuan siswa mengenai pemahaman matematika setelah mengikuti pelatihan MAPLE. Diharapkan hasil post-test yang dilakukan oleh siswa mengalami peningkatan dibandingkan hasil pre-test.

6. Uji-t berpasangan

Untuk mengetahui pengaruh dari kegiatan pelatihan ini akan dilakukan pengujian secara statistik dengan menggunakan analisis data berpasangan. Pengujian 
bertujuan untuk menguji hipotesis bahwa kegiatan pelatihan berpengaruh terhadap hasil belajar siswa SMA Negeri 8 Kota Bengkulu.

Pengujian dua rataan dapat dilakukan apabila datanya berpasangan. Dalam tiap pasangan ini, persyaratan kedua perlakuan dikenakan secara acak dalam satuan yang homogen. Perhitungan selang kepercayaan untuk $\mu_{1}-\mu_{2}$ dalam hal ini didasarkan pada peubah acak.

$$
T=\frac{\bar{D}-\mu_{D}}{S_{d} \sqrt{n}}
$$

Bila $\bar{D}$ dan $S_{d}$ peubah acak yang menyatakan rataan sampel dan simpangan baku dari selisih pengamatan dalam satuan percobaan. Seperti pada uji-t gabungan, anggapannya ialah bahwa pengamatan dari tiap populasi adalah normal. Permasalahan dua-sampel pada dasarnya disederhanakan menjadi permasalahan satu sampel dengan menggunakan selisih $d_{1}, d_{2}, \ldots, d_{n}$. Jadi hipotesisnya berbentuk

$$
H_{0}: \mu_{D}=d_{0}
$$

Uji statistik hasil perhitungan menjadi

$$
t=\frac{\bar{d}-d_{0}}{s_{d} \sqrt{n}}
$$

Daerah kritis dibuat dengan menggunakan distribusi t dengan derajat kebebasan n1 .

\section{HASIL DAN PEMBAHASAN}

Kegiatan pengabdian ini berupa pembinaan dalam bentuk upaya dan strategi untuk meningkatkan pemahaman dan hasil belajar bidang matematika siswa SMA Negeri 8 Kota Bengkulu. Kegiatan ini bermanfaat bagi siswa untuk menambah wawasan dan pengetahuan pada mata pelajaran matematika yang berkesan momok menakutkan bagi sebagian besar siswa. Manfaat yang juga dapat dirasakan oleh pihak sekolah adalah dapat membantu kegiatan ekstra kurikuler matematika yang merupakan program pengembangan diri siswa sekolah.

Kegiatan ini telah dilaksanakan di SMA Negeri 8 Kota Bengkulu yang beralamat di Jl. W.R. Supratman Pematang Gubernur Kecamatan Muara Bangkahulu Kota Bengkulu. Peserta dari kegiatan ini adalah 30 siswa SMA Negeri 8 Kota Bengkulu yang dipilih oleh guru mata pelajaran matematika. Hal ini dilakukan karena guru yang mengasuh mata pelajaran tersebut lebih mengetahui potensi dan perkembangan siswa. Seleksi dilakukan dengan tujuan mendapatkan peserta yang memiliki kemampuan rata-rata di bidang matematika dan mempunyai laptop, mengingat fasilitas komputasi di sekolah ini terbatas. Kegiatan dijadwalkan dilakukan pada hari Selasa di SMA Negeri 8 Kota Bengkulu, setiap pulang sekolah pukul 14.00 sampai dengan selesai, waktu tersebut dipilih agar tidak mengganggu jalannya proses belajar mengajar di sekolah. 


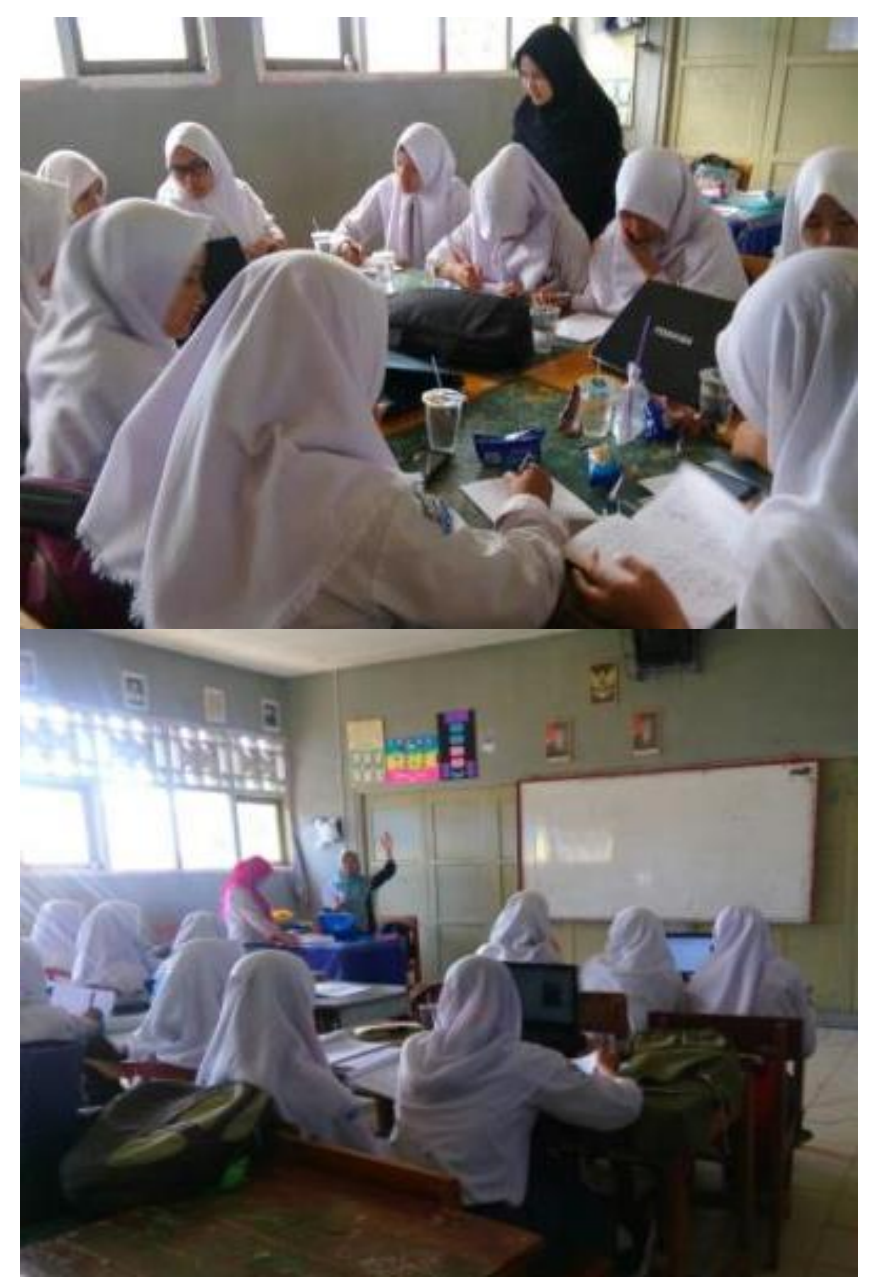

Gambar 1. Suasana pre-test (kiri) dan Pelatihan di SMA Negeri 8 Kota Bengkulu (kanan)

Pada kegiatan pertama dilakukan pre-test untuk melihat kemampuan siswa dalam mengerjakan soal secara manual. Hasilnya menunjukkan kurangnya kemampuan siswa. Perbincangan sekilas dengan siswa memberikan informasi kurangnya minat siswa pada bidang matematika dan adanya anggapan bahwa matematika merupakan bidang yang sulit bagi mereka. Kegiatan kemudian dilanjutkan dengan menunjukkan bagaimana penyelesaiannya dengan menggunakan program MAPLE. Kegiatan pertama ini diakhiri dengan penginstalan program MAPLE. Peserta sangat antusias mengenal program ini.

Kegiatan kedua diisi dengan pengenalan program dan penjelasan secara umum mengenai materi-materi dalam modul pelatihan. Adapun yang menjadi materi dalam pelatihan ini adalah: Bilangan, Himpunan, Geometri, dan Statistika. Pada kegiatan kedua ini disampaikan materi bilangan dan himpunan. Siswa sangat antusias mempelajari langkah demi langkah, syntax demi syntax, dan intruksi demi intruksi yang diberikan tim sehingga pelatihan berjalan dengan sangat lancar. Banyak pertanyaan yang disampaikan siswa selama pelatihan. Pertemuan ketiga berlangsung pada minggu berikutnya, dengan materi lanjutan yang ada pada modul. Antusias siswa tidak berkurang. Mereka cenderung 
bersemangat dan penasaran untuk mencoba bentuk-bentuk soal yang makin beragam. Pada pertemuan keempat, siswa mulai bertanya tentang masalah-masalah di luar bahasan modul. Seperti mengenai Diferensial, Integral, dan pengaplikasiannya pada volume benda putar serta bagaimana visualisasinya. Tim menjawab pertanyaan demi pertanyaan yang muncul dan menunjukkan syntax yang digunakan. Kegiatan pada pertemuan keempat ini diakhiri dengan post-test. Siswa mengerjakan soal post-test dengan bantuan MAPLE.

Dari hasil kegiatan dan pantauan langsung yang dilakukan oleh tim dapat disimpulkan bahwa minat dan pemahaman siswa SMA Negeri 8 Kota Bengkulu di bidang matematika cenderung masih kurang. Dasar pemantauan ini adalah dari hasil pre-test yang dilakukan di awal kegiatan. Dari soal yang diberikan, rata-rata siswa hanya bisa mengerjakan kurang dari separuhnya. Setelah dilakukan pre-test, siswa juga diajak diskusi mengenai soal yang telah mereka kerjakan. Hampir seluruh siswa peserta test sebenarnya telah mengenal bentuk soal yang diberikan namun mereka masih kesulitan dalam menjawab soal yang ada.

Waktu yang diberikan untuk mengerjakan soal adalah 30 menit. Sebagian dari waktu yang diberikan tidak digunakan siswa untuk menyelesaikan soal dikarenakan mereka tidak memahaminya. Oleh karena itu hampir seluruh siswa menganggap bahwa Matematika itu susah dan membingungkan. Setelah mengikuti pre-test, siswa mengikuti tahap pengenalan dan pelatihan MAPLE. Pada waktu pelaksanaan pelatihan, beberapa siswa tidak mengikuti pelatihan secara full time, dikarenakan mengikuti kegiatan sekolah lainnya. Hal ini menambah kuat anggapan tim bahwa minat belajar matematika di SMA Negeri 8 Kota Bengkulu memang kurang. Namun ini yang kemudian menjadi tantangan dan dijawab oleh MAPLE. MAPLE menjadi alat bantu untuk belajar sehingga diharapkam dapat mengurangi anggapan siswa mengenai matematika yang kurang menyenangkan. MAPLE tidak hanya memberikan pemecahan persoalan-persoalan aljabar, trigonometri, maupun diferensial dan integral, tetapi juga dapat memberikan visualisasi yang menarik dari bentuk-bentuk grafik yang dapat ditampilkan.

Dari hasil post-test yang dilakukan di pertemuan ke-empat dapat disimpulkan bahwa pelatihan memberikan hasil yang positif. Hal ini dapat dilihat dari hasil post-test yang diberikan. Dibandingkan dengan hasil pre-test, nilai post-test jauh meningkat. Sehingga dapat disimpulkan bahwa siswa sudah mulai mengenal dan memahami soal serta pelatihan MAPLE yang diberikan menjadikan siswa sudah mulai berusaha untuk mengerjakan dan menyelesaikan dengan benar.

Tabel 1. Output SPSS untuk deskripsi statistik nilai pre-test dan post-test

\begin{tabular}{|c|c|c|c|c|c|}
\hline & & Mean & $\mathrm{N}$ & Std. Deviation & Std. Error Mean \\
\hline \multirow[t]{2}{*}{ Pair 1} & Nilai_Posttest & 100.00 & 30 & .000 & .000 \\
\hline & Nilai_Pretest & 45.70 & 30 & 12.352 & 2.255 \\
\hline
\end{tabular}


Tabel 2. Output SPSS untuk pengujian dua sampel berpasangan

\begin{tabular}{|c|c|c|c|c|c|c|c|c|}
\hline & \multicolumn{5}{|c|}{ Paired Differences } & \multirow[b]{3}{*}{$\mathrm{t}$} & \multirow[b]{3}{*}{ df } & \multirow{3}{*}{$\begin{array}{l}\text { Sig. (2- } \\
\text { tailed) }\end{array}$} \\
\hline & \multirow[b]{2}{*}{ Mean } & \multirow{2}{*}{$\begin{array}{c}\text { Std. } \\
\text { Deviation }\end{array}$} & \multirow{2}{*}{$\begin{array}{l}\text { Std. Error } \\
\text { Mean }\end{array}$} & \multicolumn{2}{|c|}{$\begin{array}{l}\text { 95\% Confidence } \\
\text { Interval of the } \\
\text { Difference }\end{array}$} & & & \\
\hline & & & & Lower & Upper & & & \\
\hline $\begin{array}{cc}\text { Pair } 1 & \text { Nilai_Posttest - } \\
& \text { Nilai_Pretest }\end{array}$ & 54.300 & 12.352 & 2.255 & 49.688 & 58.912 & 24.079 & 29 & .000 \\
\hline
\end{tabular}

Analisis lebih lanjut dengan menggunakan SPSS yang dilakukan terhadap data hasil post-test ini menunjukkan bahwa ada perbedaan yang signifikan dari hasil belajar sebelum dan setelah mengenal dan menggunakan MAPLE. Dapat dilihat dari Tabel 1 berikut ini bahwa nilai rata-rata post-test adalah 100, yang jauh lebih besar jika dibandingkan dengan nilai pre-test siswa yaitu 45,70. Apabila dilakukan pengujian sampel berpasangan diperoleh nilai t-hitung 24.079 dengan p-value 0.000 , seperti yang ditampilkan oleh Tabel 2. Karena $p$-value lebih kecil dari 5\%, maka dapat disimpulkan bahwa rata-rata nilai pretest dan post-test berbeda nyata. Hal ini berarti kegiatan pengenalan dan pelatihan MAPLE di SMA Negeri 8 Kota Bengkulu memberikan pengaruh nyata terhadap hasil belajar matematika siswa.

\section{KESIMPULAN DAN SARAN}

\section{Kesimpulan}

Setelah mengadakan kegiatan pengabdian ini diperoleh kesimpulan bahwa sebagian besar siswa memang mempunyai minat dan kemampuan bidang matematika yang kurang. Faktor-faktor yang mempengaruhi kurangnya minat dan kemampuan siswa salah satunya adalah karena kurangnya alat bantu belajar matematika. Dengan kata lain tidak kenalnya mereka dengan fasilitas belajar matematika selain buku teks pelajaran. Tidak seperti beberapa bidang ilmu lain yang mempunyai fasilitas laboratorium. Dengan adanya kegiatan pengenalan dan pelatihan MAPLE ini, siswa tertarik belajar matematika dengan menggunakan MAPLE dan dapat menyelesaikan beberapa persoalan matematika dengan MAPLE. Rata-rata hasil post-test berbeda secara signifikan dengan rata-rata hasil pre-test, dimana rata-rata hasil post-test lebih baik. Hal ini berarti kegiatan pengenalan dan pelatihan MAPLE di SMA Negeri 8 Kota Bengkulu memberikan pengaruh nyata terhadap hasil belajar matematika siswa.

\section{Saran}

Saran yang dapat diajukan setelah melaksanakan kegiatan ini adalah perlunya dilakukan kegiatan berkelanjutan yang terus memotivasi, memantau dan mengembangkan pengetahuan siswa dalam bidang matematika. 


\section{UCAPAN TERIMA KASIH}

Terima kasih disampaikan kepada Lembaga Pengabdian Pada Masyarakat Universitas Bengkulu yang telah mendanai kegiatan ini melalui PNBP Universitas Bengkulu Nomor: SP. DIPA-042.01.2.400977/2016.

\section{DAFTAR PUSTAKA}

Anonim, 2007, MAPLE Getting Started Guide, Canada, Waterloo MAPLE Inc.

Ulum, Asep Saeful, 2015, Mengapa Matematika Terasa Sulit? http://www.kompasiana.com/asepmathema/mengapa-matematika-terasa-sangatsulit_550d8c53a33311811b2e3bd9, Diakses pada tanggal 14 Maret 2016 